\title{
Estudo Comparativo da Resistência ao Desgaste Abrasivo do Revestimento de Três Ligas Metálicas Utilizadas na Indústria, Aplicadas por Soldagem com Arames Tubulares
}

\author{
(Comparative Study of the Wear Resistance of Three Metal Cored Wire Welded Coatings Used in Industry)
}

\author{
Ricardo Vinícius de Melo Leite1, Paulo Villani Marques² \\ ${ }^{1}$ Eutectic, Pesquisa e desenvolvimento, Contagem, MG, Brasil, ricardo.leite@eutectic.com.br \\ ${ }^{2}$ Universidade Federal de Minas Gerais, Departamento de Engenharia Mecânica, Belo Horizonte, MG, Brasil, pvillani@ufmg.br
}

\begin{abstract}
Resumo
As ligas metálicas aplicadas por soldagem em superfícies, objetivando a proteção contra o desgaste e o conseqüente aumento da vida útil de peças e equipamentos, têm sido utilizadas em larga escala nas indústrias de bens de consumo e nos setores de mineração e sucroalcooleiro. O desgaste abrasivo em peças e equipamentos representa, nestas industriais, um dos principais fatores de depreciação de capital e uma importante fonte de despesas com manutenção. Para a aplicação do revestimento por soldagem, os arames tubulares têm sido uma alternativa cada vez mais viável, devido à sua alta produtividade e qualidade de solda, substituindo, em parte, o uso do eletrodo revestido. O objetivo deste trabalho é fazer um estudo comparativo da resistência ao desgaste abrasivo do revestimento aplicado por soldagem com arames tubulares autoprotegidos de três ligas metálicas utilizadas na indústria, uma do tipo Fe-Cr-C, outra do tipo $\mathrm{Fe}$ - $\mathrm{Cr}$-C com adição de nióbio e boro e a terceira, do tipo $\mathrm{Fe}$-Cr-C com adição de nióbio. Os revestimentos anti-desgaste, conhecidos como revestimento duro, foram aplicados em chapas de aço carbono, com os mesmos parâmetros e procedimentos de soldagem. Os corpos de prova foram obtidos por corte e retificação e foram submetidos a ensaios de desgaste abrasivo, em um abrasômero Roda de Borracha, conforme procedimento estabelecido pela norma ASTM G65-91. Os resultados obtidos demonstraram que a liga $\mathrm{Fe}$-Cr-C com adição de Nióbio e Boro apresentou desempenho superior em relação ao desgaste abrasivo.
\end{abstract}

Palavras-chave: Arame tubular; liga $\mathrm{Fe}$-Cr-C; revestimento duro; roda de borracha; desgaste abrasivo

\begin{abstract}
The metal alloys deposited by welding on the components surface, with the objective of protection against wear and the consequent increase in the lifetime of parts and equipments, have been used extensively in the consumer products industry and sectors of Mining and Sugar \& alcohol. The abrasive wear on parts and equipments represents one of the main depreciation factors of capital and the major source of expenditure on maintenance in industries. For the application of the coating by welding, cored wire have been a viable alternative, because of its high productivity and high weld quality, replacing in part, the use of the stick electrode. The objective of this work is to make a comparative study of the abrasive wear resistant coating deposited by welding with selfshielded cored wires of three metal alloys used in industry, first the $\mathrm{Fe}-\mathrm{Cr}$-C alloy, the second the $\mathrm{Fe}$-Cr-C alloy with niobium and boron addition, and the third the $\mathrm{Fe}$-Cr-C with niobium addition. The wear resistant coatings, known as hardfacing were deposited on carbon steel plates, with the same parameters and procedures of welding. The samples were obtained by cutting and grinding and were subjected to abrasive wear tests, in a Rubber Wheel apparatus, according to procedure established by ASTM G65-91. The results showed that the $\mathrm{Fe}-\mathrm{Cr}$-C alloy with Niobium and Boron addition presented superiority in terms of wear resistence.
\end{abstract}

Key-words: Fe-Cr-C alloy; cored wire; hardfacing; abrasive wear; Rubber Wheel testing.

\section{Introdução}

Fricção e desgaste são fenômenos tão antigos quanto a humanidade. No paleolítico, fogo era gerado pela fricção de madeira em madeira ou pedra [1]. Na antiga mesopotâmia

(Recebido em 05/07/2009; Texto Final em 08/12/2009). Publicado com permissão da ABCM - Associação Brasileira de Engenharia e Ciências Mecânicas - Artigo originalmente apresentado no $5^{\circ}$ COBEF, Belo Horizonte, MG, Abril de 2009 existiram alguns sofisticados equipamentos tribológicos. Os antigos egípcios também fizeram uso da fricção para transporte de pesadas cargas e existem muitas figuras que demonstram que a sociedade apreciava o uso da lubrificação para reduzir o desgaste em contatos de deslizamento e rolagem [2].

Atualmente nota-se um interesse cada vez maior na otimização econômica dos processos de produção, sendo que a cada dia é dada uma maior atenção a todos os fatores que interferem nos custos, na qualidade final do produto e no meio ambiente. Dentre os segmentos industriais nesta situação estão os de produção de bens de consumo, e os prestadores de serviço, 
que se utilizam de processos de soldagem, destacando-se as indústrias de mineração, sucroalcooleira e de produção de aços. Nessas indústrias, o desgaste é um fenômeno que pode causar danos consideráveis em seus componentes e equipamentos. $\mathrm{O}$ desgaste representa um dos principais fatores de depreciação de capital e de fontes de despesas com manutenção. Segundo Gregolin [3], ele influi nos custos diretos de produção devido às necessidades de reposição ou recuperação de peças desgastadas, e também nos custos indiretos de produção pela necessidade de superdimensionamento de componentes e pelas limitações na produção devido a equipamentos deteriorados, além de interrupções muitas vezes imprevistas nas linhas de produção.

Enumeram-se quatro mecanismos pelos quais os componentes e equipamentos industriais podem perder sua utilidade: obsolescência, quebra, corrosão e desgaste. Este último, já mencionado, assume papel relevante devido à sua complexidade e também à dificuldade de sua investigação [4]. Segundo Eyre [5], o desgaste pode ser definido como a degradação da superfície do componente ou do equipamento, geralmente envolvendo remoção progressiva do material, como resultados de processos tribológicos. Eyre observou que o desgaste do tipo abrasivo é a mais freqüente forma de ocorrência em inúmeros segmentos industriais, contribuindo com cerca de 50\% dos problemas industriais envolvendo desgaste.

Um método de combate a este fenômeno, tecnicamente chamado de revestimento, é a deposição de uma liga especial na superfície sujeita a esta deterioração. Isto pode ser obtido pela aplicação de cordões de solda na superfície, ou pela aplicação de placas metálicas protetoras, revestidas com componentes resistentes ao desgaste, denominando-se revestimento duro. Como o desgaste abrasivo é um resultado geralmente intrínseco das operações e dos processos onde ocorrem, seu controle e minimização dependem essencialmente da seleção de materiais e processos apropriados [4,5]

A característica que distingue o processo de soldagem por Arame Tubular de outros processos de soldagem a arco consiste no fluxo encerrado dentro de um arame que é alimentado continuamente. $\mathrm{O}$ processo oferece duas variações que diferem no método de proteção do arco (arame autoprotegido e com proteção gasosa). No tipo autoprotegido a proteção do metal fundido é feita pela decomposição e vaporização de componentes do fluxo do eletrodo pelo calor do arco. No outro tipo, com proteção gasosa, faz-se uso de uma nuvem de gás protetor em adição à ação do fluxo do eletrodo [6].

O processo Arame Tubular agrega as principais vantagens do MIG/MAG, como elevados valores de taxa de deposição, rendimento e fator de trabalho do soldador, possibilitando a obtenção de alta produtividade e alta qualidade de solda. Além disso, apresenta características da soldagem manual com eletrodos revestidos, como a possibilidade de ajustes da composição química do cordão de solda, a facilidade de aplicação em campo e a alta versatilidade [6]. Segundo Conde [7], na aplicação de revestimentos duros, os arames tubulares têm sido preferidos por apresentarem maior produtividade que com eletrodos revestidos e maior flexibilidade que com arco submerso e, além disso, apresentarem menor aporte térmico, menos distorções e zona termicamente afetada (ZTA).
As ligas com alto $\mathrm{Fe}-\mathrm{Cr}-\mathrm{C}$ são particularmente atrativas para a aplicação de revestimentos duros porque podem formar uma grande variedade de micro-constituintes (carbonetos), provendo um aumento da resistência à abrasão [8].

Nos revestimentos em multicamadas estudados por Buchely et al [9] observou-se uma tendência de maior resistência ao desgaste abrasivo para os revestimentos de maior dureza. Entretanto, diversos autores, dentre os quais Kotecki e Ogborn [10] afirmam que, embora o aumento da dureza possa resultar em aumento da resistência ao desgaste, particularmente quando se compara revestimento duro aplicado sobre substrato de aço médio carbono, diferentes revestimentos com durezas similares podem ter diferentes resistências ao desgaste. Por outro lado, Buchanan et al [8] destacam que, apesar da maior dureza do revestimento hipereutético (710 HV300) sobre o hipoeutético (450 HV300) em liga FeCrC, não se observou clara superioridade deste sobre o menos duro. Isso reforça que, apesar da importância da dureza, não é esta que governa as propriedades de resistência ao desgaste, especialmente o abrasivo de baixa tensão, mas sim, a microestrutura.

Com o objetivo de dar continuidade à linha de pesquisa descrita anteriormente, este trabalho têm como objetivo fazer um estudo comparativo, em termos de resistência ao desgaste abrasivo, de três ligas metálicas comerciais aplicadas por arames tubulares, utilizadas na prevenção e recuperação de equipamentos industriais que sofrem a ação do desgaste abrasivo.

\section{Materiais e métodos}

\subsection{Soldagem dos corpos de prova}

Para obtenção dos corpos de prova, foram produzidas três placas de desgaste, através do processo de soldagem com arames tubulares autoprotegidos (FCAW) de 2,8 mm de diâmetro, de três ligas metálicas.

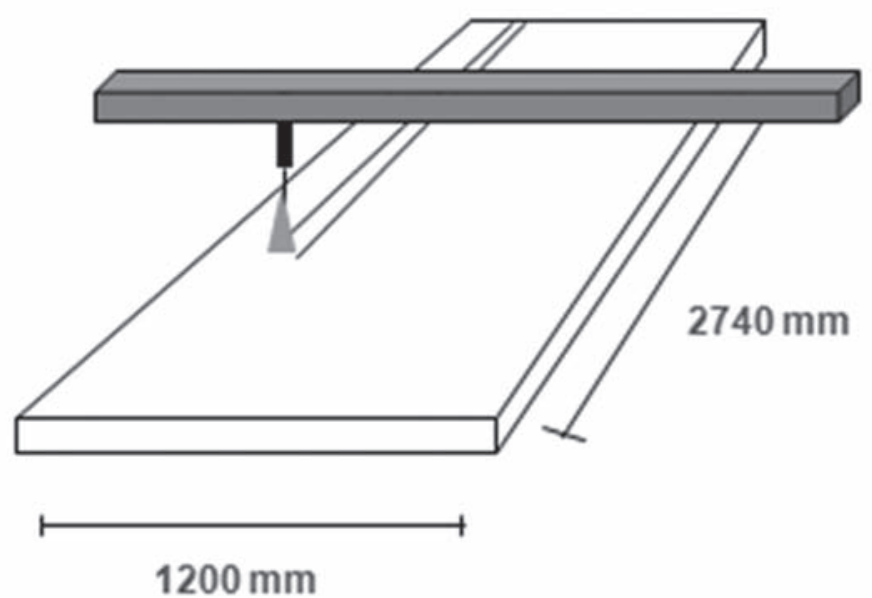

Figura 1. Representação esquemática da produção de um chapa de desgaste.

A primeira, denominada de liga A, é constituída de $\mathrm{Fe}-\mathrm{Cr}-$ Nb-B-C, a segunda, denominada de liga B, constituída de Fe$\mathrm{Cr}-\mathrm{C}$ e a terceira, liga $\mathrm{C}$, constituída de $\mathrm{Fe}-\mathrm{Cr}-\mathrm{Nb}-\mathrm{C}$. 
As placas revestidas de aço A36 com dimensões 6,0 x 1220 x $2740 \mathrm{~mm}$ foram fabricadas com a deposição de uma camada única de $4 \mathrm{~mm}$ de solda em uma chapa de aço A36 de $6 \mathrm{~mm}$ de espessura, obtendo-se então uma peça com $10 \mathrm{~mm}$ de espessura total. A pequena diluição medida após a deposição apresentou-se semelhante para as três ligas, não sendo uma variável importante neste estudo comparativo. A soldagem foi feita com cordões de $2740 \mathrm{~mm}$ de comprimento, $30 \mathrm{~mm}$ de largura, e com os mesmos parâmetros de soldagem, mostrados na Tabela 1, para as três ligas estudadas. Durante a soldagem, as chapas foram postas sobre uma mesa resfriadora, para controle das propriedades do metal depositado, particularmente a microestrutura. A figura 1 mostra de forma esquemática a produção de uma placa de desgaste, com deposição de revestimento duro sobre chapa de aço A36.
Para obtenção de uma confiabilidade do teste de $95 \%$, estimou-se através da Equação (1) o número mínimo de corpos de prova necessários para um coeficiente de variação $(v)$ de $5 \%$ e um erro permitido de amostras (e) de 5\%, conforme sugerido nos textos da ASTM G65-91 [11].

$$
\mathrm{n}=(1,96 . \mathrm{v} / \mathrm{e})^{2}
$$

De cada placa fabricada foram retiradas 5 amostras (corpos de prova) da região central, nas dimensões de 10 x 25 x 75 mm e usinadas para obter-se uma superfície uniforme, conforme norma ASTM G65-91 [11], para avaliação do desgaste através do teste da "roda de borracha". A Figura 2 ilustra parte dos corpos de prova obtidos, após corte e usinagem.

Tabela 1. Parâmetros de soldagem para produção das placas revestidas.

\begin{tabular}{|c|c|c|c|c|}
\hline PLACA & $\begin{array}{l}\text { Diâmetro } \\
(\mathrm{mm})\end{array}$ & $\begin{array}{l}\text { Veloc. Alimentação } \\
(\mathrm{cm} / \mathrm{min})\end{array}$ & $\begin{array}{l}\text { Veloc. Soldagem } \\
(\mathrm{cm} / \mathrm{min})\end{array}$ & $\begin{array}{l}\text { Corrente } \\
\text { (A) }\end{array}$ \\
\hline LIGA A (FeCrNbBC) & \multirow{3}{*}{2,8} & \multirow{3}{*}{470} & \multirow{3}{*}{20} & \multirow{3}{*}{290} \\
\hline LIGA B ( $\mathrm{FeCrC})$ & & & & \\
\hline LIGA C (FeCrNbC) & & & & \\
\hline
\end{tabular}

Tabela 2. Parêmetros de teste utilizados no equipamento "roda de borracha"

\begin{tabular}{|c|c|c|c|c|c|}
\hline $\begin{array}{c}\text { Duração } \\
(\mathrm{min})\end{array}$ & $\begin{array}{c}\text { Carga } \\
(\mathrm{N})\end{array}$ & $\begin{array}{c}\text { Velocidade Roda } \\
\text { Abrasiva (rpm) }\end{array}$ & $\begin{array}{c}\text { Granulometria } \\
\text { Areia (mesh) }\end{array}$ & $\begin{array}{c}\text { Dureza Borracha } \\
\text { (shore) }\end{array}$ & $\begin{array}{c}\text { Diâmetro Roda } \\
\text { Abrasiva (mm) }\end{array}$ \\
\hline 28 & 130 & 215 & 32 & 13,4 & 221,3 \\
\hline
\end{tabular}

\subsection{Testes de desgaste abrasivo}

Nos testes de abrasão utilizou-se um abrasômero tipo Roda de Borracha, ilustrado na Figura 3, que é recomendado para simulação de desgaste abrasivo a baixas tensões, utilizando-se de areia seca como partícula abrasiva, conforme norma ASTM G65-91 [11]. Os parâmetros de teste utilizados são apresentados na Tabela 2 .

\section{Resultados e discussão}

Além dos resultados de desgaste abrasivo dos revestimentos, serão apresentados resultados de análise química, e dos ensaios de dureza e micrografia das ligas estudadas.

\subsection{Dureza e composição química}

Foram feitas 5 medições de dureza Rockwell $\mathrm{C}$ em cada corpo de prova, totalizando 25 medições em cada liga estudada. As médias dos valores obtidos para dureza, com os respectivos desvios padrões são apresentadas na tabela 3. A liga metálica que apresentou a maior dureza foi a liga $\mathrm{A}, \mathrm{Fe}-\mathrm{Cr}-\mathrm{Nb}-\mathrm{B}-\mathrm{C}$.

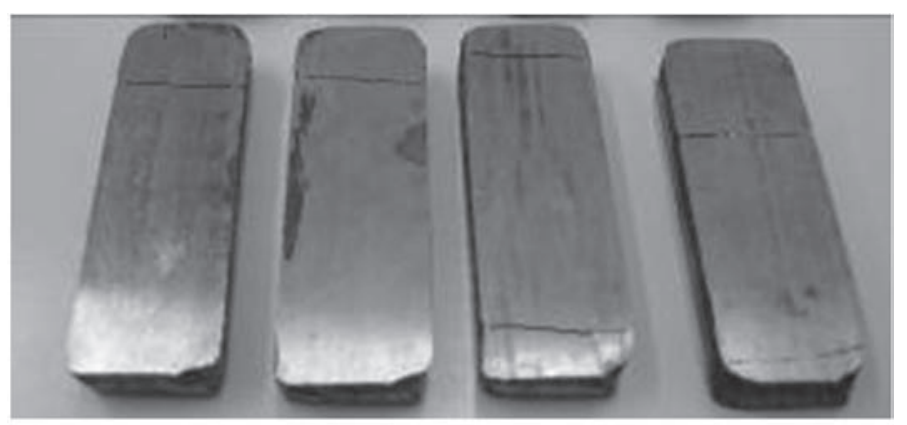

Figura 2. Parte dos corpos de prova obtidos para testes de abrasão.

Tabela 3. Resultados de dureza dos corpos de prova das ligas A, B e C.

\begin{tabular}{|c|c|c|}
\hline Corpo de prova & Dureza média (HRC) & $\begin{array}{c}\text { Desvio } \\
\text { padrão }\end{array}$ \\
\hline LIGA A & 61 & 0,3 \\
\hline LIGA B & 58 & 0,4 \\
\hline LIGA C & 50 & 0,6 \\
\hline
\end{tabular}




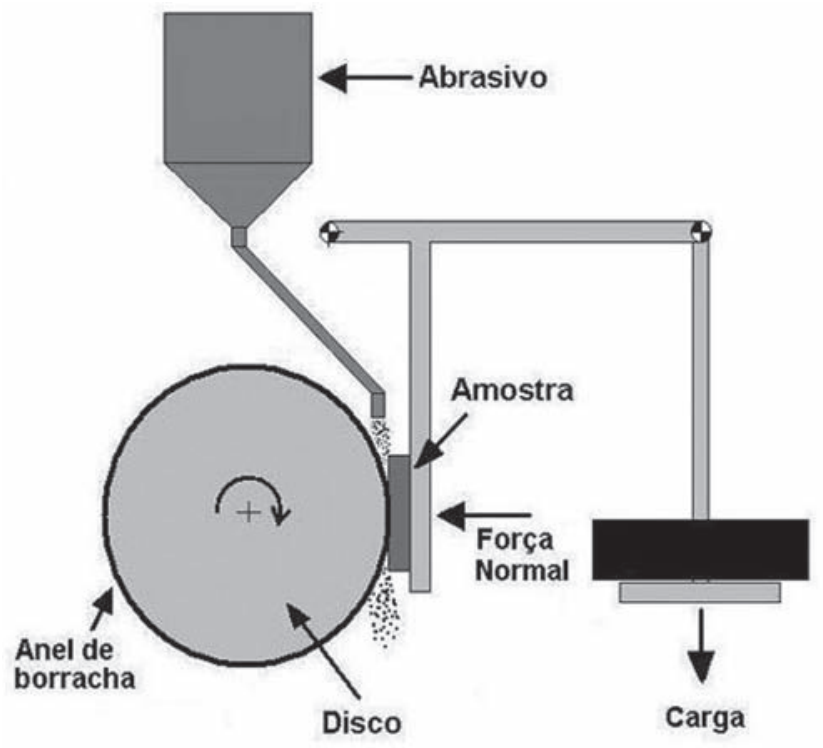

(a)

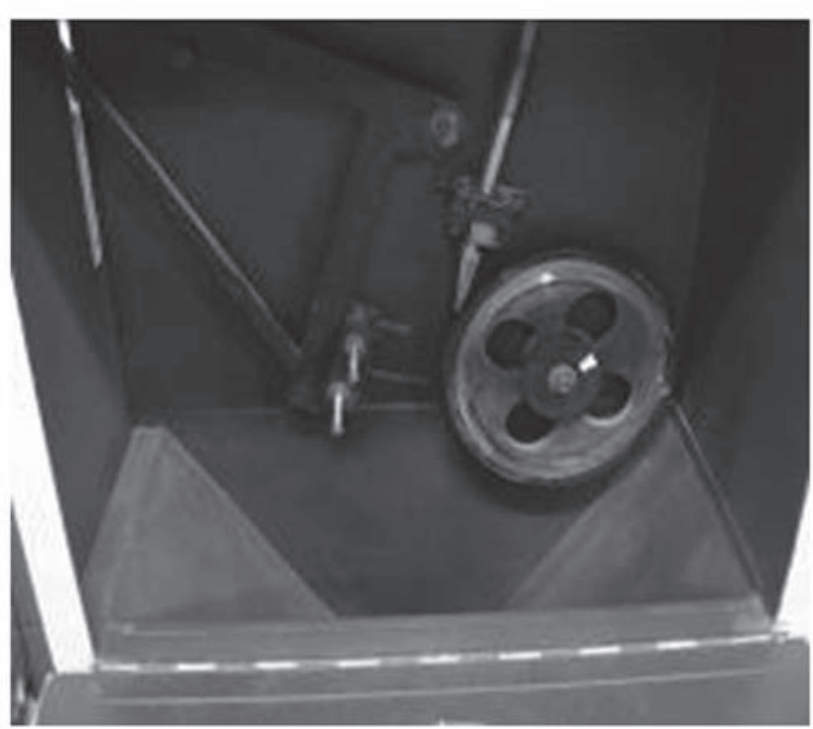

(b)

Figura 3. Esquema do abrasômetro Roda de Borracha (a) e equipamento utilizado nos ensaios (b).

Tabela 4. Valores de composição química das placas revestidas

\begin{tabular}{|c|c|c|c|c|c|c|c|}
\hline \multirow{2}{*}{ Tipo de liga } & \multirow{2}{*}{ Corpo de Prova } & \multicolumn{6}{|c|}{ Composição química (\%) } \\
\cline { 3 - 8 } Fe-Cr-Nb-B-C & A & 3,10 & 19,00 & 0,50 & 6,0 & 0,60 & 0,10 \\
\hline Fe-Cr-C & B & 3,05 & 20,00 & 0,42 & - & - & 0,20 \\
\hline Fe-Cr-Nb-C & C & 1,90 & 7,30 & 0,40 & 5,90 & - & 0,90 \\
\hline
\end{tabular}

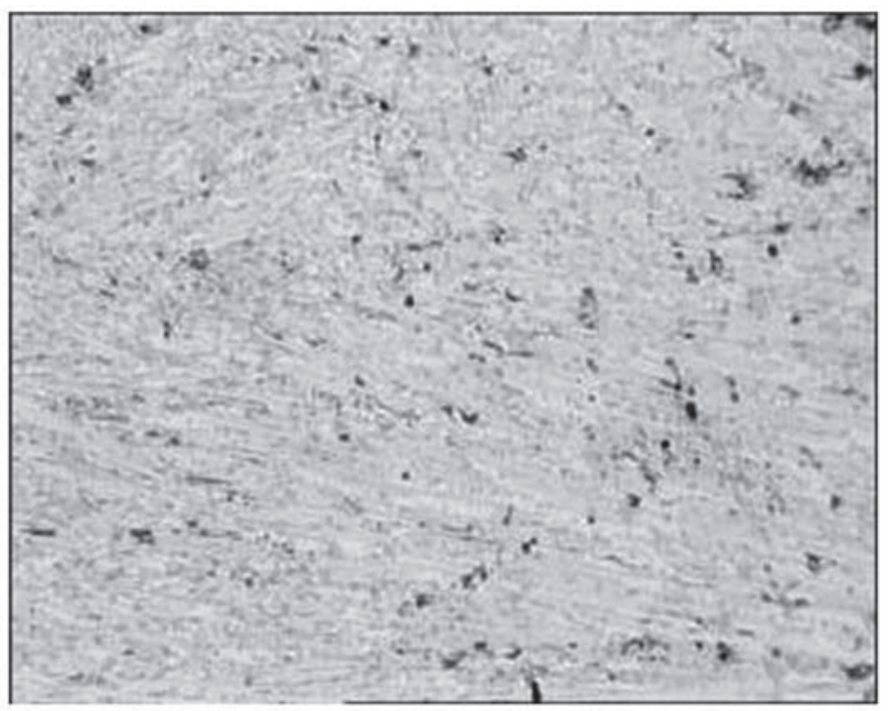

(a)

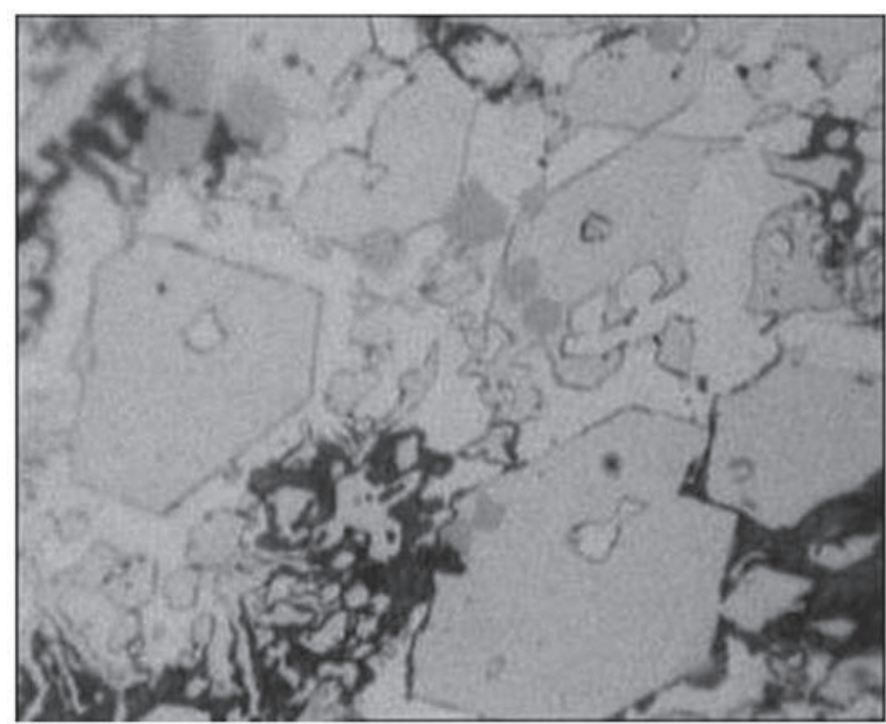

(b)

Figura 4. Microestrutura do revestimento com a liga A. Aumento: (a) 200X e (b) 1000X. Ataque: Nital 2\%. (MO). 
As análises químicas das superfícies dos revestimentos testados foram obtidas pelo método de emissão óptica. O resultado é mostrado na tabela 4.

\subsection{Análise metalográfica}

A análises metalográficas das ligas A, B e C, foram feitas através de microscopia óptica (MO) e são apresentadas nas figuras 4, 5 e 6 respectivamente, com aumentos de 200 e 1000 vezes e o reagente utilizado em todas elas foi o nital $2 \%$. Podese observar na Figura 4 que a microestrutura da liga $\mathrm{A}(\mathrm{Fe}-\mathrm{Cr}-$ $\mathrm{Nb}-\mathrm{B}-\mathrm{C})$ é formada por carbonetos poligonais e prismáticos

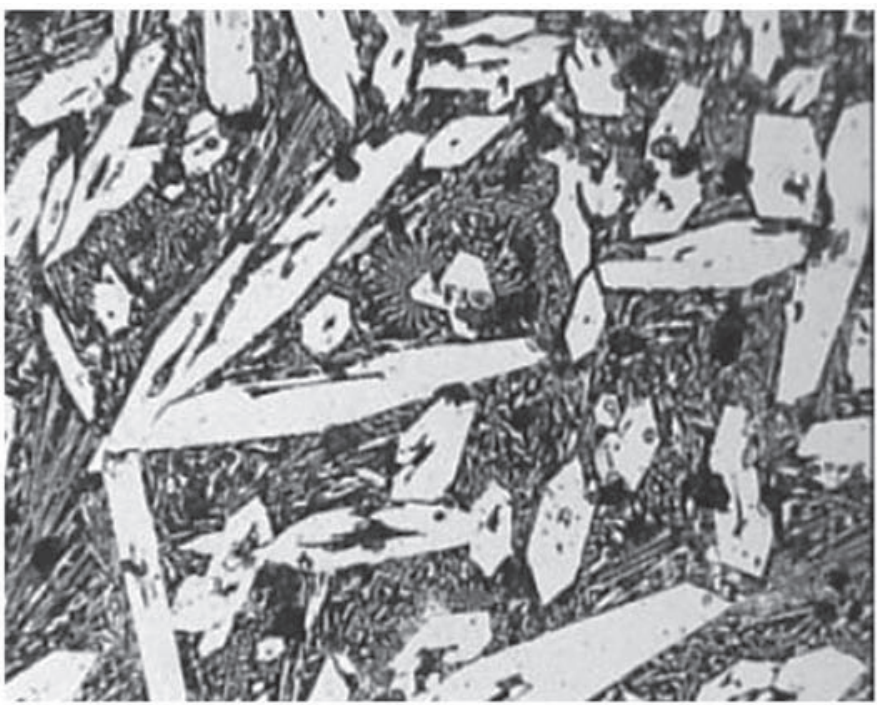

(a) de ferro e cromo (áreas claras), constituinte eutético formado por carbonetos de $\mathrm{Fe}-\mathrm{Cr}$, austenita e martensita (áreas escuras). Nota-se ainda a presença de carbonetos de nióbio na forma de polígonos de tonalidade rosa. A estrutura na superfície se mostra do tipo hipereutética.

Na Figura 5 observa-se a microestrutura do revestimento com a liga $\mathrm{B}$ (Fe-Cr-C), constituída de carbonetos poligonais e prismáticos de ferro e cromo (áreas claras) e constituinte eutético formado por carbonetos de Fe-Cr, austenita e martensita (áreas escuras). A estrutura na superfície se mostra do tipo hipereutética.

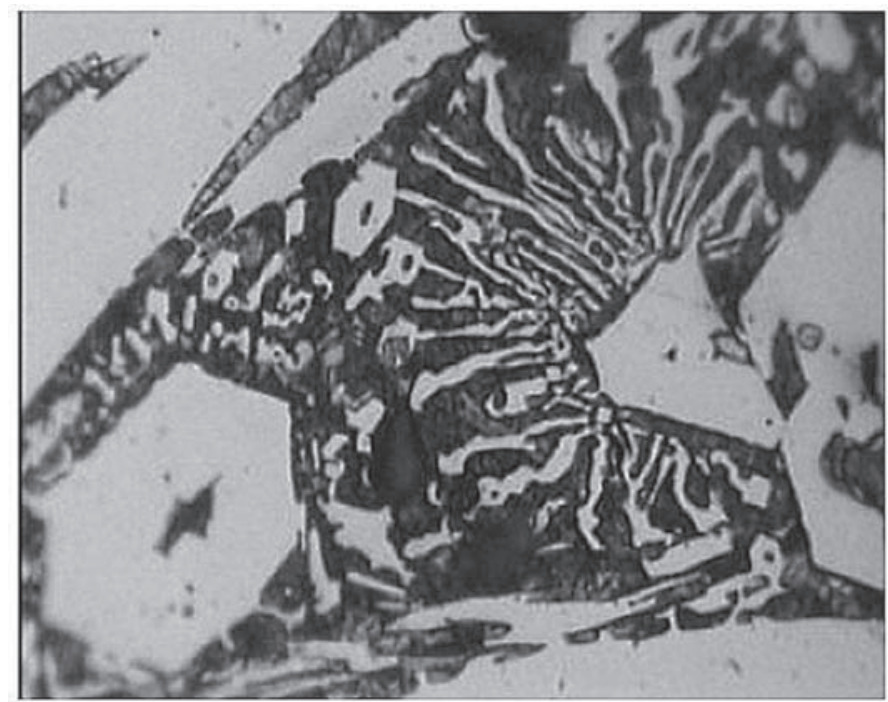

(b)

Figura 5. Microestrutura do revestimento com a liga B. Aumento: (a) 200X e (b) 1000X. Ataque: Nital 2\%. (MO).

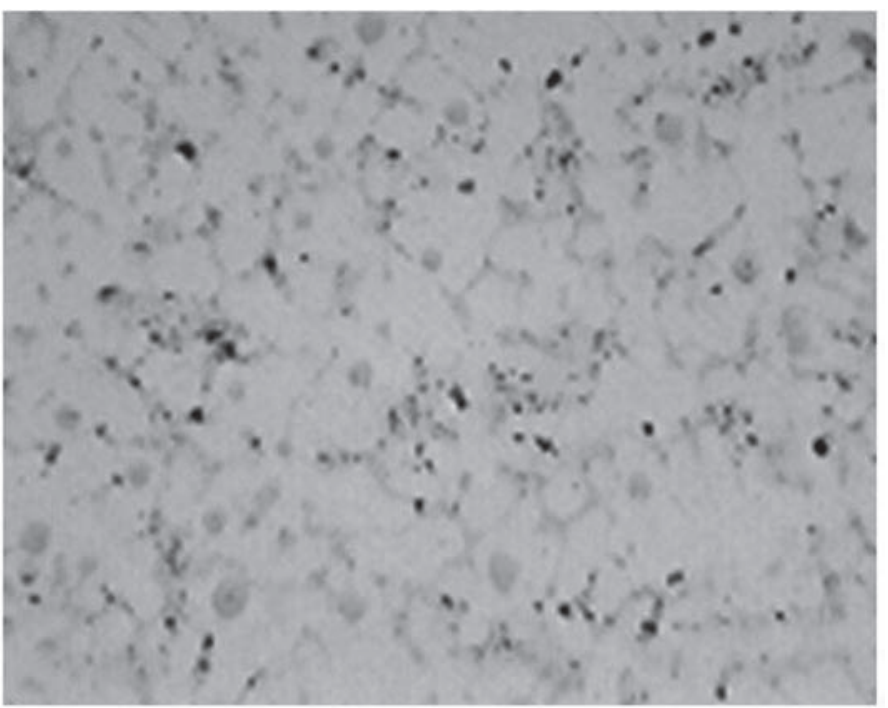

(a)

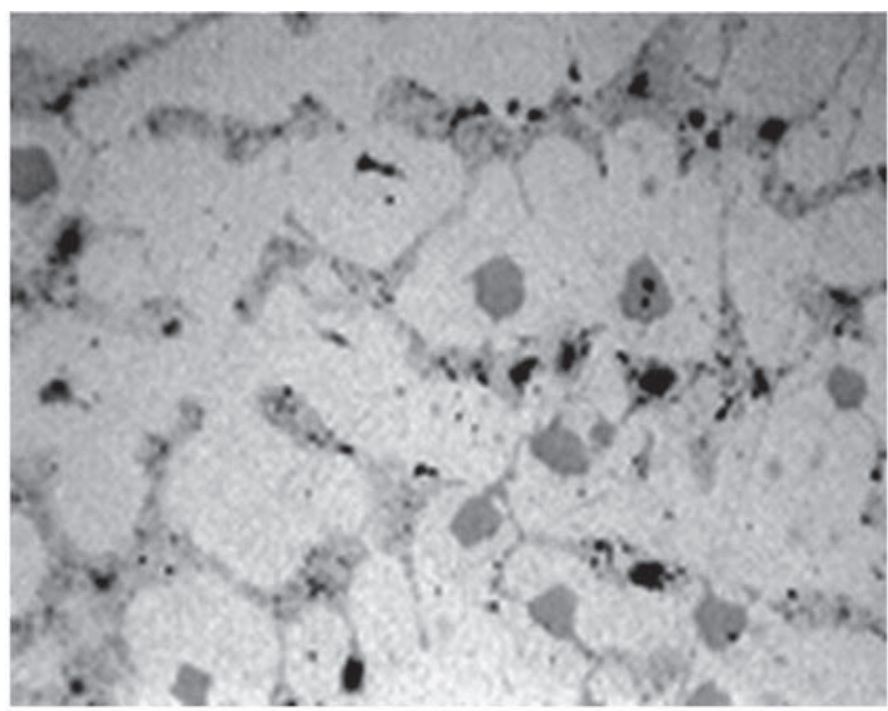

(b)

Figura 6. Microestrutura do revestimento com a liga C. Aumento: (a) 200X e (b) 1000X. Ataque: Nital 2\%. (MO). 
Nota-se, na figura 6 a presença de carbonetos primários de nióbio, representados pelos pontos de tonalidade rosa e constintuínte eutético, representado pela área de tonalidade cinza-escuro. A microestrutura possivelmante é formada por uma matriz de martensita, embora o ataque não tenha revelado características típicas deste constintuínte, que é sugerida pelo alto valor de dureza e peloo comportamento magnético do material.

Os resultados dos ensaios de desgaste abrasivo a baixas tensões são mostrados na Tabela 5 e de forma gráfica na Figura 7. Pode se observar que os valores de desvio padrão e de coeficiente de variação, obtidos para as três amostras através das Equações (2) e (3), estão dentro dos limites estabelecidos pela norma ASTM G65-91 [11], e indicam que o procedimento e o equipamento (abrasômero) utilizados estão corretamente calibrados e foram capazes de fornecer resultados sem interferências. Observa-se também que a liga $\mathrm{A}$ apresentou, em todas as amostras, valores inferiores de perda de volume, quando comparada com as ligas $\mathrm{B}$ e $\mathrm{C}$, indicando uma maior resistência ao desgaste abrasivo desta liga, nas condições de teste apresentadas neste trabalho.

$$
\begin{aligned}
S & =\sqrt{\sum(x-\bar{x})^{2}} / n-1 \\
& =(s / \bar{x}) 100
\end{aligned}
$$

onde $\mathrm{S}=$ desvio padrão da média e = Coeficiente de variação $(\%)$.

\begin{tabular}{|c|c|c|c|c|c|}
\hline $\begin{array}{c}\text { Corpo de } \\
\text { prova }\end{array}$ & Liga & $\begin{array}{c}\text { Perda de } \\
\text { volume } \\
\left(\mathrm{mm}^{3}\right)\end{array}$ & $\begin{array}{c}\text { Média da perda } \\
\text { de volume } \\
\left(\mathrm{mm}^{3}\right)\end{array}$ & $\begin{array}{l}\text { Desvio } \\
\text { Padrão }\end{array}$ & $\begin{array}{c}\text { Coef. de } \\
\text { Variação } \\
(\%)\end{array}$ \\
\hline A1 & \multirow{5}{*}{$\mathrm{Fe}-\mathrm{Cr}-\mathrm{Nb}-\mathrm{B}-\mathrm{C}$} & 5,94 & \multirow{5}{*}{5,62} & \multirow{5}{*}{0,32} & \multirow{5}{*}{5,64} \\
\hline A2 & & 5,98 & & & \\
\hline A3 & & 5,64 & & & \\
\hline A4 & & 5,24 & & & \\
\hline A5 & & 5,29 & & & \\
\hline B1 & \multirow{5}{*}{$\mathrm{Fe}-\mathrm{Cr}-\mathrm{C}$} & 7,09 & \multirow{5}{*}{6,91} & \multirow{5}{*}{0,36} & \multirow{5}{*}{5,30} \\
\hline B2 & & 7,07 & & & \\
\hline B3 & & 6,93 & & & \\
\hline B4 & & 7,15 & & & \\
\hline B5 & & 6,30 & & & \\
\hline $\mathrm{C} 1$ & \multirow{5}{*}{$\mathrm{Fe}-\mathrm{Cr}-\mathrm{Nb}-\mathrm{C}$} & 5,94 & \multirow{5}{*}{6,31} & \multirow{5}{*}{0,35} & \multirow{5}{*}{5,63} \\
\hline $\mathrm{C} 2$ & & 6,13 & & & \\
\hline $\mathrm{C} 3$ & & 6,20 & & & \\
\hline $\mathrm{C} 4$ & & 6,49 & & & \\
\hline $\mathrm{C} 5$ & & 6,77 & & & \\
\hline
\end{tabular}

Tabela 5. Resultados do teste de desgaste abrasivo das amostras das ligas A, B e C.

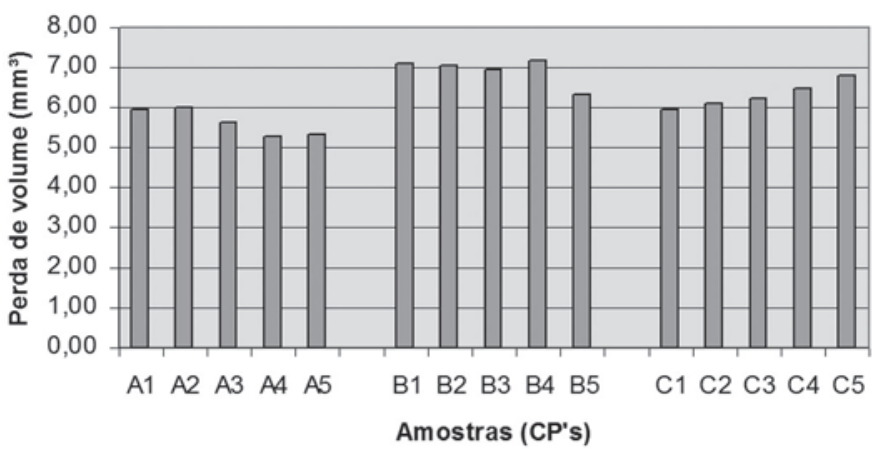

Figura 7. Avaliação comparativa de desgaste abrasivo dos corpos de prova das ligas A, B e C.
A validade do tamanho da amostra estimada, para uma confiança de $95 \%$ (erro $n=5 \%$ ), foi verificada através da Equação (1), utilizando os valores de coeficiente de variação obtidos, apresentando os seguintes resultados:

$$
\begin{aligned}
& n A=(1,96 . / e)^{2}=(1,96.5,64 / 5)^{2}=4,9 \\
& n B=(1,96 . / e)^{2}=(1,96.5,30 / 5)^{2}=4,3 \\
& n C=(1,96 . / e)^{2}=(1,96.5,63 / 5)^{2}=4,9
\end{aligned}
$$

onde $n A, n B$ e $n C$ representam o número de ensaios, ou o tamanho de amostra das ligas $\mathrm{A}, \mathrm{B}$ e $\mathrm{C}$ respectivamente.

Com estes resultados, pode-se afirmar que o tamanho de amostra escolhido (5 amostras para cada liga), em um nível de $95 \%$ de confiança, foi adequado para a representação e 
repetibilidade dos resultados.

A maior resistência ao desgaste abrasivo da liga A deve estar associada, além das presenças de carbono e cromo nas quantidades encontradas, à presença de elementos como Nióbio e Boro na estrutura, que segundo Gregory [12] estão associados a uma microestrutura com características específicas na resistência ao desgaste abrasivo a baixas tensões. De acordo com os resultados dos testes de microscopia óptica e de varredura, pôde-se notar a presença de carbonetos primários de nióbio na liga A. Segundo Eyre [5] o carboneto primário de nióbio, $\mathrm{NbC}$, possui dureza de $2400 \mathrm{HV}$, superior, por exemplo, à dureza do carboneto primário de cromo, $\mathrm{Cr}_{7} \mathrm{C}_{3}$, que possui dureza de $1800 \mathrm{HV}$. Chatterjee e Pal [13] comprovaram que o $\mathrm{NbC}$ atua também como nucleador e refinador do carboneto de cromo, quando este elemento existe na composição da liga, aumentando consideravelmente a proteção da matriz com carbonetos refinados.

Das três ligas analisadas, a liga B foi a que apresentou maiores valores de perda de volume e conseqüentemente menor resistência ao desgaste abrasivo a baixas tensões, nos testes realizados.

A liga $\mathrm{C}$, embora sua microestrutura não esteja relacionada àquela descrita por Koteck e Ogborn [10], que apresenta melhor resistência ao desgaste abrasivo a baixas tensões, contendo carbonetos primários em uma matriz austenítica mais carbonetos, apresentou resistência ao desgaste superior à da liga $\mathrm{B}$, que se enquadra em tal descrição. A superioridade na resistência ao desgaste abrasivo da liga $\mathrm{C}$, em relação à liga $\mathrm{B}$ pode estar associada à presença de carbonetos de nióbio na estrutura, que, segundo Chatterjee e Pal [13], além de proteger a matriz, têm uma influência na nucleação de carbonetos de cromo refinados caso este elemento exista na composição do material, aumentando a resistência a abrasão a baixas tensões.

$\mathrm{O}$ fato de a liga $\mathrm{B}$, que representa uma liga Hipereutética ter apresentado menor resistência ao desgaste abrasivo do que a liga $\mathrm{C}$, que representa uma liga Hipoeutética, também pode estar associado, segundo Fiori et al. [14], ao fato do microtrincamento e fragmentação dos grandes carbonetos primários $\mathrm{M}_{7} \mathrm{C}_{3}$, que podem atuar como abrasivos, promovendo sulcamento e riscamento na superfície da liga depositada.

\section{Conclusão}

A partir dos dados obtidos, pode-se chegar às seguintes conclusões:

- A liga $\mathrm{A}(\mathrm{FeCrNbBC})$ apresentou uma maior resistência ao desgaste abrasivo, comparada as ligas $\mathrm{B}(\mathrm{FeCrC})$ e $\mathrm{C}$ ( $\mathrm{FeCrNbC}$ ), nas condições de testes descritas neste trabalho.

- A presença de nióbio e boro na liga A contribuiu significativamente para uma maior resistência ao desgaste, quando comparada com a liga B uma vez que os outros elementos químicos destas duas ligas são bem parecidos, em tipo e quantidade ( $\mathrm{Fe}, \mathrm{Cr}$ e $\mathrm{C}$ ).

- A Liga C, apesar de apresentar dureza superficial média menor que a da liga $\mathrm{B}$, apresentou maior resistência ao desgaste abrasivo a baixas tensões, nas condições dos testes realizados.
- A liga A, que apresentou maior resistência ao desgaste abrasivo, também mostrou maiores valores de dureza.

\section{Referências bibliográficas}

[1] GAHR, Karl-Heinz Zum. Microestruutre and wear of materials Tribology series, v10. Amsterdam: Elsevier, 1987. p.560.

[2]. WILLIANS, J. A. Engineering tribology. Oxford: oxford publications, 1994. p.488).

[3]. GREGOLIN, J. A. R. - Desenvolvimento de ligas Fe-C-Cr$\mathrm{Nb}$ Resistentes ao Desgaste. Tese de doutorado, Universidade Estadual de Campinas (1990).

[4]. NOBLE, D. N. - The Effect of flux-cored Arc Welding Condictions on Microstructure and abrasive Wear Resistance of Two Iron-Based hardfacing Alloys. The Welding Institute Research Report, p.1-18. November 1986.

[5] EYRE, 1978. EYRE T. S. - Wear Characteristic of Metals, Source Book on Wear Control Tecnology, ASM, Metals Park, Ohio - Usa, (1978).

[6] AWS - American Welding Society, Welding Handbook Welding Processes, vol.2; 8a edição, USA, 955p, 1991.

[7] CONDE, R.H. Recubrimentos Resistentes al Desgaste, Boletim Técnico Conarco, Buenos Aires, Argentina, Año 12, ${ }^{\circ}$ 85, 40 pp., 1986.

[8] BUCHANAN, V. E., SHIPWAY P. H. e Mc CARTNEY, D. G. Microstructure and Abrasive Wear Behaviour of Shielded Metal Arc Welding Hardfacings Used in the Sugarcane Industry. Wear.12.053; 2006, p. 1-12, 2006.

[9] BUCHELY, M. F. GUTIERREZ, J. C. LEÓN, L. M. e TORO, A. The Effect of Microstructure on Abrasive Wear of Hardfacing Alloys. Tribology International. Vol. 259, p. 52-61, 2005.

[10] KOTECKI D. J. e OGBORN, J. S. Abrasion Resistance of Iron Based Hardfacing Alloy. Welding Journal. p. 269s - 278s. (8) aug. 1995.

[11] ASTM, Standard Test Method for Measuring Abrasion Using The Dry Sand/Rubber Wheel Aparatus, ASTM G65-91, p. 231-243, 1991.

[12] GREGORY, E. N. - Selection of Materials for Hardfacing. Welding Surfacing and Hardfacing. The Welding Institute. 88p, December 1980.

[13] CHATTERJEE, S. and PAL, T.K - Wear Behaviour of Hardfacing Deposits on Cast Iron. Wear. 255 p. 417-425, 2003. [14] FIORI, N. F. et al. The Effect of Carbide Volume Fraction on Low Stress Abrasion Resistance of High Cr-Mo White Cast Irons. Wear. 84, p.313-325, 1983. 